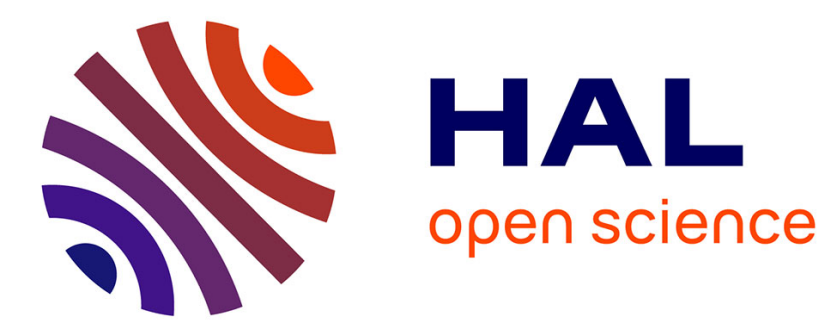

\title{
Premixed flames propagating freely in tubes
}

\author{
Christophe Almarcha, Bruno Denet, Joel Quinard
}

\section{To cite this version:}

Christophe Almarcha, Bruno Denet, Joel Quinard. Premixed flames propagating freely in tubes. Combustion and Flame, 2015, 162 (4), pp.1225-1233. 10.1016/j.combustflame.2014.10.010 . hal01216525

\section{HAL Id: hal-01216525 \\ https://hal.science/hal-01216525}

Submitted on 16 Oct 2015

HAL is a multi-disciplinary open access archive for the deposit and dissemination of scientific research documents, whether they are published or not. The documents may come from teaching and research institutions in France or abroad, or from public or private research centers.
L'archive ouverte pluridisciplinaire HAL, est destinée au dépôt et à la diffusion de documents scientifiques de niveau recherche, publiés ou non, émanant des établissements d'enseignement et de recherche français ou étrangers, des laboratoires publics ou privés. 


\title{
Premixed flames propagating freely in tubes
}

\author{
Almarcha C., Denet B., Quinard* J. \\ Aix Marseille Université, CNRS, Centrale Marseille, IRPHE UMR 7342, 13384, Marseille, France \\ Corresponding author: quinard@irphe.univ-mrs.fr \\ IRPHE - UMR 7342 - CNRS-AMU et ECM \\ 49 rue F. Joliot-Curie, BP 146 \\ 13384 Marseille FRANCE \\ Tel (33)-4 13552021
}

\begin{abstract}
$\underline{\text { Abstract }}$
This paper reports an experimental investigation of premixed propane and methane-air flames propagating freely in tubes $1.5 \mathrm{~m}$ long and with diameters 54 and $94 \mathrm{~mm}$. Two regimes of propagation are distinguished by correlating the flame speed and the radius of curvature at the flame tip. The characteristic lengths are then related to the cut-off wavelengths estimated from linear theories and compared to previous results of Michelson-Sivashinsky simulations.
\end{abstract}

Keywords: Premixed flame speed; front dynamics; instabilities; nonlinearity, Darrieus-Landau instability

\section{Introduction}

The role of the hydrodynamic flame instability for premixed turbulent burning in gas turbine, spark ignition engines or industrial burners has been widely discussed $[1,2]$. This effect is caused by thermal expansion through the flame front and is the most essential factor in the flame instability, together with the diffusivethermal effect that stabilizes the short-wavelengths perturbations depending on the Lewis number of the deficient reactant. Now, there is a mounting evidence that the flame instability is of primary importance for turbulent burning, leading for example to an increase by a factor of 10 of the flame propagation velocity of free expanding turbulent spherical flames [3,4]. It was also suggested that this instability plays an important role in the rapid increase of $U_{t} / U_{L}$ with pressure in high-pressure environments [5], where $U_{t} / U_{L}$ is the ratio of the turbulent flame speed to the laminar flame speed. Even weakly wrinkled flames maintain values of $\mathrm{U}_{\mathrm{t}} / \mathrm{U}_{\mathrm{L}} \sim 3-4$ down to very low values of the turbulence level $\mathrm{u}^{\prime} / \mathrm{U}_{\mathrm{L}}[6]$.

These combustion instabilities are relatively well described at the onset of instability, at least for some pure fuels, and can be handled in some direct numerical simulations, but it would be a huge task to account for them in actual burners since the characteristic length scale of the flow exceeds the typical flame thickness by many orders of magnitude.

The theoretical analysis of these flames has been successful: nonlinear model equations have been derived, first by Sivashinsky in 1977 [7] and by Frankel in 1990 [8]. Simple solutions of the Sivashinsky equation have been obtained in 1985 by Thual Frisch and Henon [9], and building on this discovery G. Joulin has studied theoretically large scale flame fronts in a number of configurations, spherical flames, oblique flames or flames of overall parabolic shape [10-13]. Numerical simulations of the Sivashinsky equation have been performed in these configurations, as they are hundred times faster than direct numerical simulations, permitting the study of very large flames [14-17]. The qualitative agreement of these simulations with experiments is excellent [18]. The observed dynamics is extremely complicated, involving cells on the flame front that continuously appear and then merge. This phenomenon possibly leads to a selfsimilar propagation of the flame with a fractal structure observed on free expanding spherical flames $[3,4]$ or in numerical simulations [19-20]. It has been proposed [6, 19-22] that weakly turbulent premixed flames also have a fractal character in other geometries.

All these approaches refer to a characteristic length scale generally defined as the cut-off length scale $\lambda_{c}$ due to the balance between Darrieus-Landau (DL) hydrodynamic instability and stabilizing effects of thermal diffusion. This characteristic length is the one and only parameter in theoretical models. It can be evaluated to $10-40 d_{L}$ from linear theories [23] where $d_{L}$ is the laminar flame thickness, but numerical solutions of these models can hardly be compared to experimental results generally obtained in turbulent flows [6, 24-27]. 
The best way for checking these models and the whole literature on the subject is to study premixed flames propagating freely in quiescent gases. The movement of a flame element will then only results from its own propagation at the normal flame speed $\mathrm{U}_{\mathrm{L}}$ and from its advection at the local gas velocity produced by hydrodynamical effects induced by the whole flame shape. A recent experiment showed that it was possible to observe an almost stationary downwards propagation of premixed methane- and propane-air flames in tubes of various diameters, thanks to a new type of acoustic damper that eliminates the thermo-acoustic instability which otherwise would produce large acceleration effects on the flame and change drastically the flame propagation [28]. The attention was paid to the velocity of propagation of axis-symmetrical flames to be compared to self-similar relations describing free flame propagation in tubes [26-27]. The normalized self-turbulent flame speed $\mathrm{U}_{\mathrm{n}}=\mathrm{U}_{\mathrm{t}} / \mathrm{U}_{\mathrm{L}}$ increased up to 2.5 while the tube diameter increases from 36 to 141 $\mathrm{mm}$, and its variation with the equivalence ratio of the gas mixture was qualitatively in agreement with a self-similar relation using as cut-off wavelength the shortest unstable wavelength calculated from linear theories. The fractal exponent was close to $1 / 3$. However, slanted flames were also observed with a much larger propagation speed, a result not expected from Sivashinsky simulations where all solutions have the same speed and for which the more slanted flame is less stable [29]. The present work aims at a better description of these two regimes of propagation by measuring simultaneously the instantaneous position of the leading flame bump and its radius of curvature. It will be shown that the flame speed is well correlated to the curvature at the leading bump. The characteristic radius of curvature at the leading bump are then related to the cut-off wavelengths and compared to the results of Michelson-Sivashinsky simulations.

\section{Experimental setup and procedure}

The propagation velocity of laminar cellular flames is measured in vertical Pyrex tubes, $1.5 \mathrm{~m}$ long, with internal diameters $\mathrm{D}_{0}$ of 54 and $94 \mathrm{~mm}$. Flames in tubes with smaller diameter would be affected by heatlosses while tubes with larger diameter can lead to secondary instabilities on the flame [28]. The equivalence ratio, $\phi$, of the premixed gas is controlled via a PC-interface connected to mass-flow regulators. The flame propagation is recorded using a high-speed video camera viewing the reflected images of the flame on two lines of sight at right angle (Fig.1). The acoustic damper at the bottom part of the burner consists of a small annular slit, of height $h$ and length $l$, that dissipates acoustic energy by terminating the tube with a real (resistive) acoustic impedance equal to the characteristic acoustic impedance of free air (see ref. 28 for details). A lightweight refractory fabric is placed over the open end of the burner to prevent mixing with ambient air while permitting the exhaust of the premixed or burnt gas.

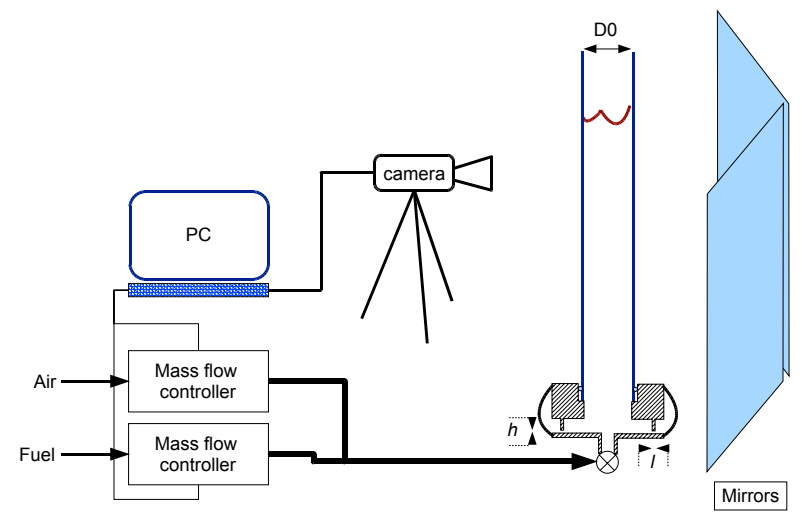

Figure 1: Experimental set-up

The procedure is as follows: after each run, the air flow is opened and maintained until the tube walls have cooled to ambient temperature. The flow of combustible, methane or propane, is then adjusted to the desired equivalence ratio and maintained for a time corresponding at least to ten fillings of the tube to ensure a homogeneous mixture. It is then stopped by closing the valve at the bottom of the burner and a delay of at least one minute is allowed before ignition to ensure that premixed gases are at rest. The ignition of the gas mixture is then performed by way of the fast discharge of a capacitor in a $0.1 \mathrm{~mm}$ radius steel wire that can be placed either on the burner axis to favour axis-symmetric flame shapes, or close to the wall to obtain slanted flames. About five runs are performed in each configuration: $\phi=(0.8,1,1.3)$, tube diameter $=(54,94) \mathrm{mm}$ and axial or lateral ignition at the top of the burner. The video is generally recorded 
at a frame rate of 250 images per second. The video movies are post-processed using Image $1.45 \mathrm{r}$ software to obtain the instantaneous position of the upstream tip of the flame and to calculate the radius of curvature in each orthogonal section of the flame (Fig.2). The effective radius of curvature is then simply obtained by

$$
2 / R_{f}=1 / R_{1}+1 / R_{2}
$$

The self-turbulent flame speed is obtained by a linear fit of the displacement of the upstream flame tip over a distance at least equal to $0.5 \mathrm{~m}$.

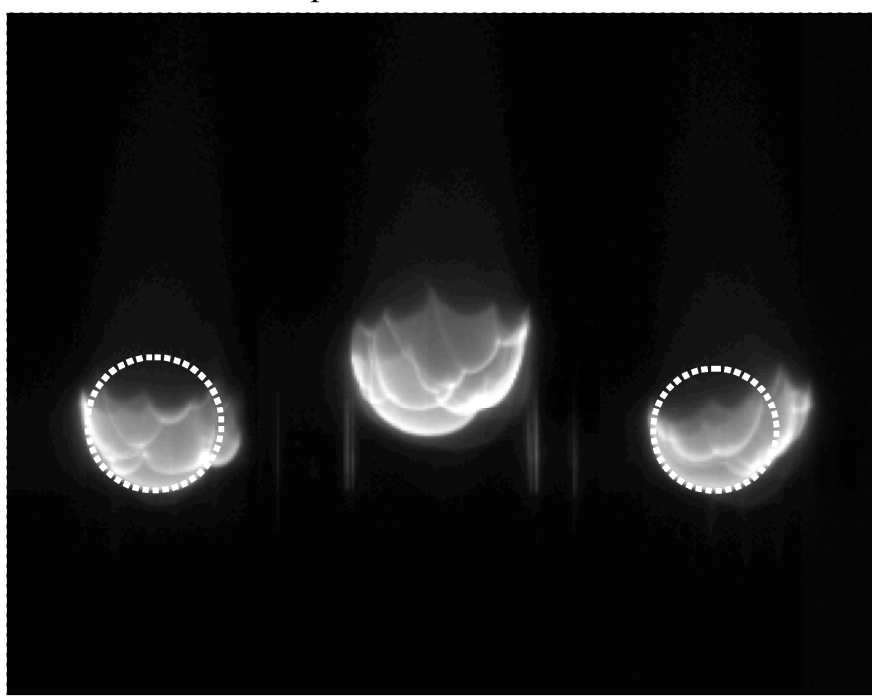

Figure 2-a

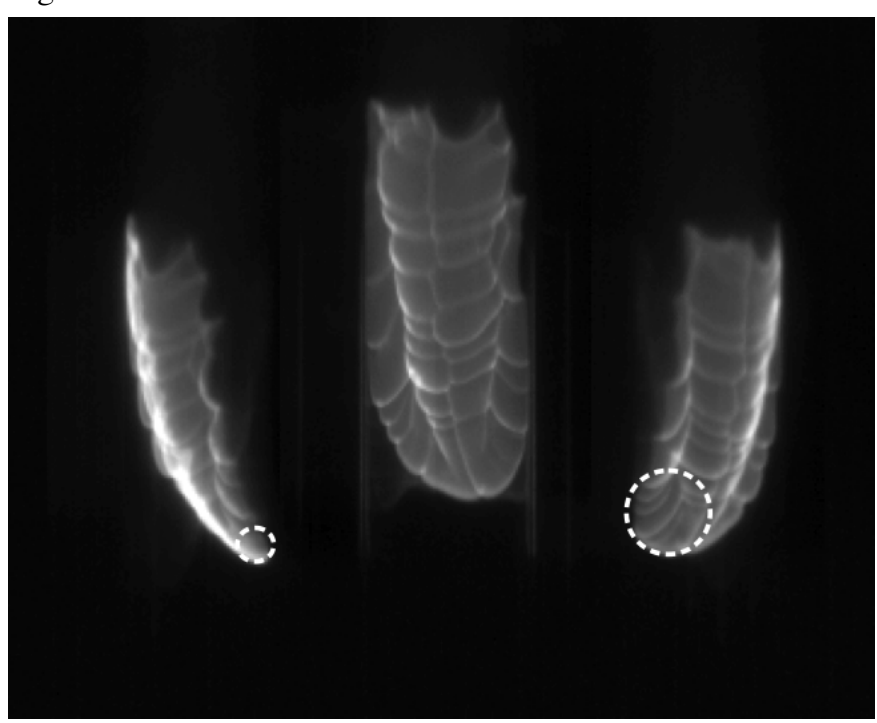

Figure 2-b

Figure 2: Image processing to determine the position of the flame tip and the radius of curvature in each orthogonal section (left and right images on each picture; middle image: direct view of the flame).

Propane-air flame, $\phi=1.0$, tube $ø 94 \mathrm{~mm}$. a) axial ignition; b) lateral ignition.

\section{Michelson-Sivashinsky simulation}

In this section, we give a brief presentation of the Michelson-Sivashinsky equation (or Sivashinsky equation, depending on the authors) that will be compared to experimental results. This equation is a model equation [7] which describes the non linear behaviour of a flame submitted to a Darrieus Landau instability. We will write this equation in a one-dimensional case. Let us imagine a two-dimensional premixed flame propagating towards fresh gases (at the bottom of the domain) in the y direction. The transverse coordinate will be denoted by $\mathrm{x}$, and the following equation for the front position $\phi(x, t)$ can be derived (the flame laminar velocity is equal to 1 , the width of the domain to $2 \pi$ )

$\phi_{t}+(1 / 2) \phi_{x}^{2}=I(\phi)+v \phi_{x x}+u(x, t)$ 
$I(\phi)$ is a pseudo differential operator (the Landau operator) corresponding to multiplication by $\mid \mathrm{kl}$ (the wave vector) in Fourier space. The first two terms on the right hand side of the equation correspond to the Darrieus Landau linear dispersion relation, $\mathrm{u}(\mathrm{x}, \mathrm{t})$ is a forcing term. The only non-linear term $(1 / 2) \phi_{x}{ }^{2}$ is geometrical and describes the normal propagation of the flame at the laminar velocity (taken to be 1 here). It is extremely simple to solve this equation numerically with Fourier pseudo spectral methods, one example will be given in the following section. Let us note that the only non-dimensional parameter of the equation is $v$, it controls the number of unstable modes in the domain. In this description what is important is the ratio domain width/ cut-off length scale and is equal to $1 / v$.

We now summarize some properties of the Michelson Sivashinsky equation. It has been found in [9] that simple solutions of this equation exist, described by a certain number of poles in the complex plane. The typical number of poles of the solution (called optimal number of poles in [29]) increases when the number of unstable modes $1 / v$ increases, so that as the ratio domain width/ cut-off length scale is increased, the solution becomes more and more complicated. Among the many solutions that have been found in [29], some solutions are linearly stable, see particularly figure 1 of [29], where slanted or almost symmetrical solutions (see the experimental results of the next section for similar solutions in the cylindrical tube) have been obtained. One interesting property of these solutions found in this article is that a moderate noise (the term $\mathrm{u}(\mathrm{x}, \mathrm{t})$ of the equation or the residual turbulence in the experiment) causes jumps between the different stationary solutions. Naturally these results are obtained for the one-dimensional Michelson-Sivashinsky equation, much less is known (see however [26]) in the cylindrical case. We will see in the next section how the experimental results compare to these predictions.

\section{Results}

\section{1: Flame speed}

The first interrogation was on the existence of slanted flames: do they evolve with a well defined velocity of propagation slightly larger than the symmetrical ones as suggested by theoretical approaches [2,27], or is there a large number of discrete solutions as those obtained from the Sivashinsky equation [29]? The flame trajectories in the tubes appear relatively rectilinear with two distinct velocities of propagation well correlated to the symmetry of the flame (Fig.3), even if the flame can transit from one mode of propagation to the other one during the experiment. Lateral ignition produces generally slanted flames, which propagate faster than almost symmetrical flames obtained after axial ignition. The same trends are observed with propane-air flames (Fig.4), but the situation is not always clear: rich propane- and lean methane-air flames are always slanted in the smaller tube, whereas rich methane-air flames are almost symmetrical.

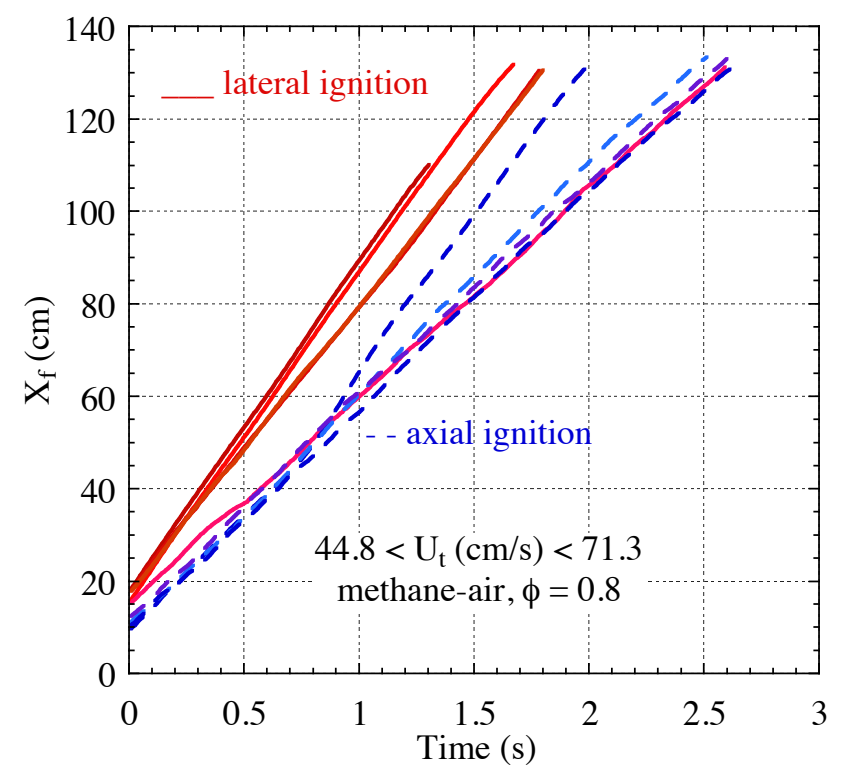

Figure 3-a 


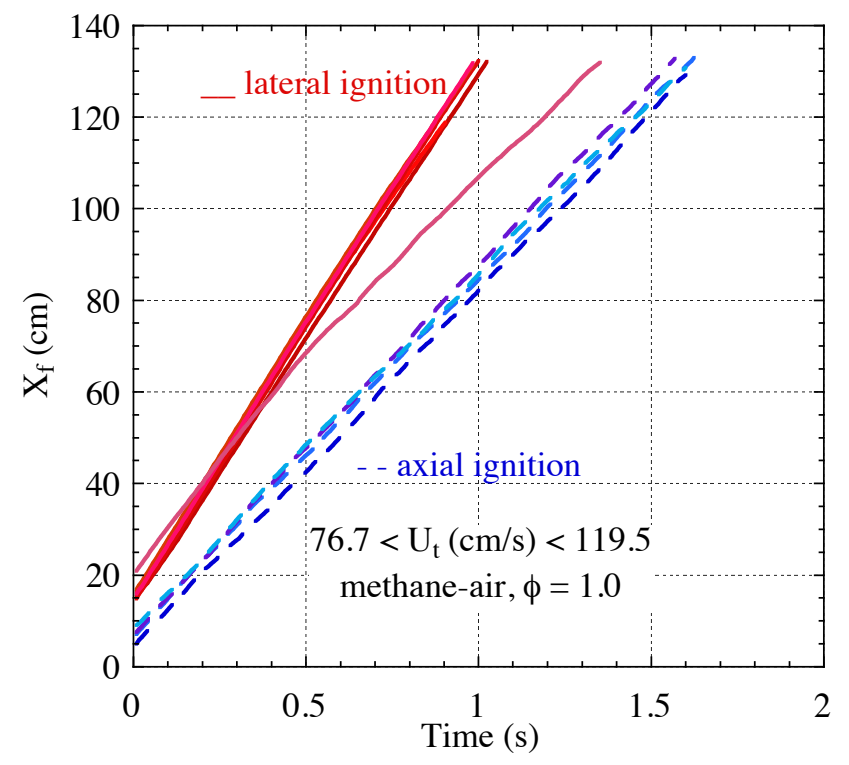

Figure 3-b

Figure 3: Trajectories of methane-air flames in a tube $\varnothing=94 \mathrm{~mm}$ as a function of initial conditions for ignition. a) $\phi=0.8$; b) $\phi=1$; full lines: lateral ignition; dashed lines: axial ignition.

There are thus essentially two velocities of propagation of premixed flames in tubes depending on the main shape of the flame. There is no indication that quasi-axis-symmetric flames are less stable than slanted ones, since a slanted flame may also transit to a quasi-symmetric flame. However it will be seen later that even slow flames obtained after axial ignition are slightly asymmetric. The measured values are in good agreement with previous measurements in the same conditions [28], except that much faster slanted flames speed were obtained here for stoichiometric propane-air flames thanks to the new type of igniter. It is worth noticing that previous measurements were done by igniting the flame with a lighter without any control of the initial condition. Slanted flames propagate at a speed 50\% larger than quasi-symmetric flames. The same trends were observed with propane-air flames (Fig.4).

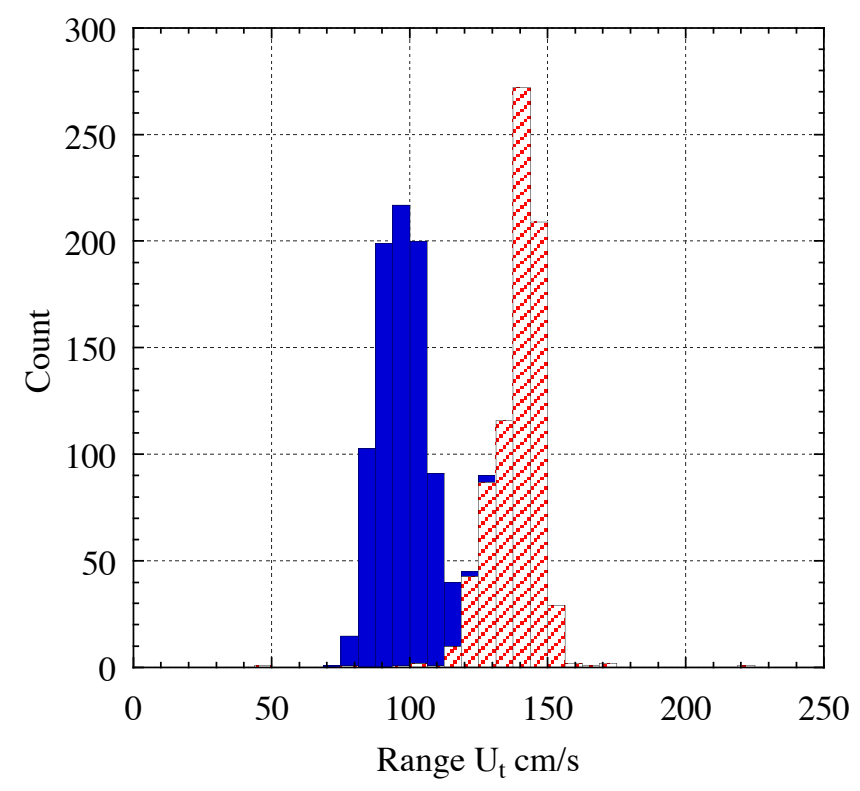

Figure 4: Histogram of stoichiometric propane-air flame velocities in a tube $\varnothing=94 \mathrm{~mm}$ as a function of initial conditions for ignition. Hatched/ full shading: lateral/ axial ignition.

A question that arises is why some flames adopt a slanted shape with a faster velocity of propagation? Looking at the simultaneous measurement of the instantaneous flame speed at the upstream tip and of the integrated luminous intensity of the flame supposed to be proportional to the whole flame surface (Fig. 5a), 
it appears that the flame speed is in advance compared to the flame surface. The same behaviour is recovered with Michelson-Sivashinsky simulations (Fig. 5b) where the total flame length fluctuations are delayed compared to the flame speed fluctuations at the leading tip. The local conditions at the tip are thus critical, controlling the flame speed at the tip that determines the length of the flame skirt and the flame surface.

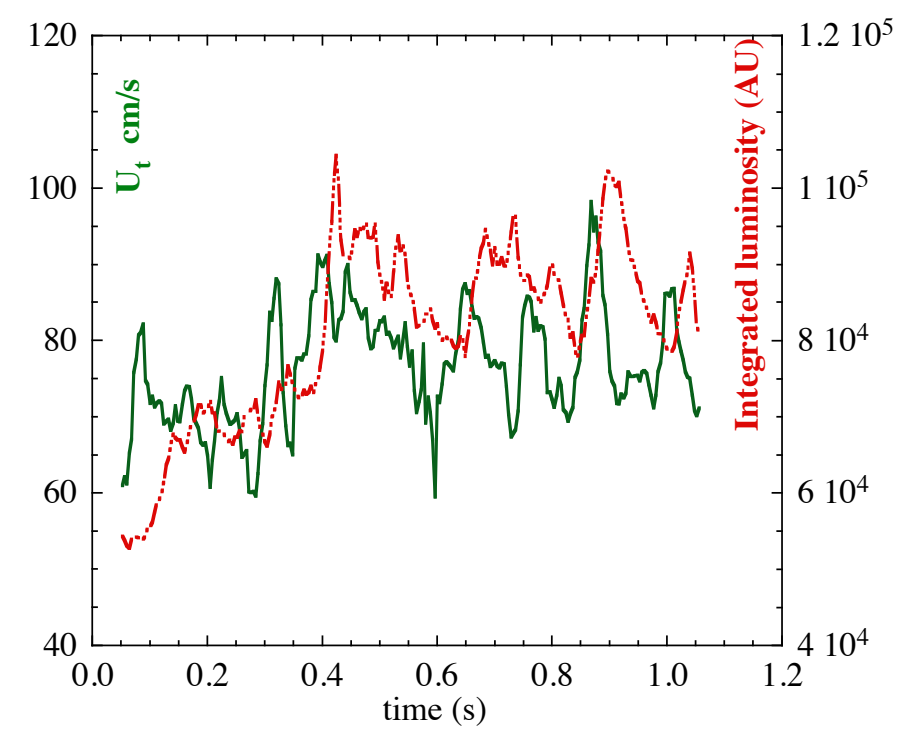

Figure 5-a

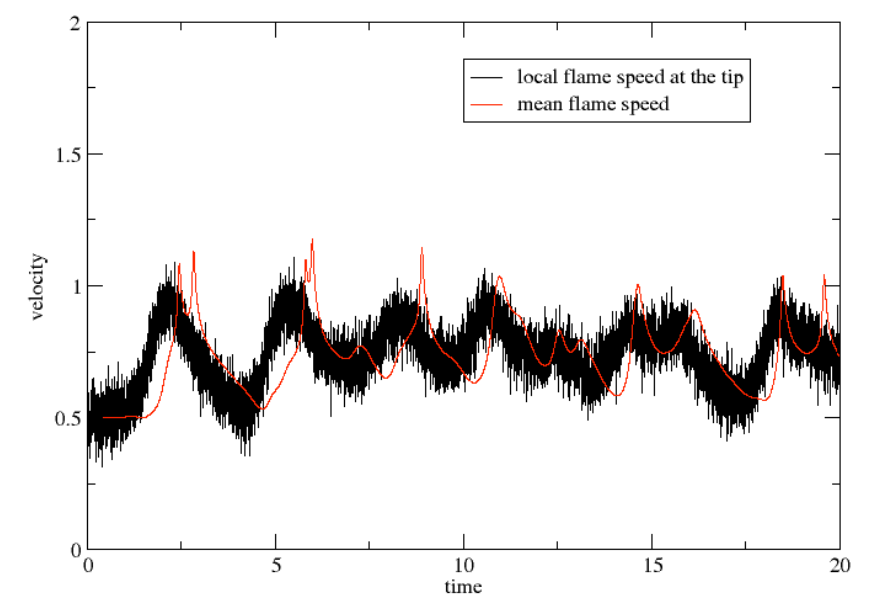

Figure 5-b

Figure 5: Time traces of the instantaneous flame speed at the tip (full line) and integrated luminosity (5-a, dash-dotted line) or mean flame speed (5-b, dash-dotted line).

a) Methane-air flame, $\phi=1$, tube $\varnothing=54 \mathrm{~mm}$; b) Michelson-Sivashinsky simulation with $10 \%$ Gaussian white noise in space and time.

\section{2: Effects of curvature}

These local conditions at the tip can be characterized by the effective radius of curvature calculated from two orthogonal views of the flame front. Whatever the dispersion of the instantaneous measurements (Fig.6-a), it appears clearly that the slowest flames are obtained with an axial ignition and have a larger (negative) radius of curvature than slanted flames obtained with lateral ignition. Here the flame speed is normalized by the laminar flame speed measured by Bosshaart and De Goey [30]. For the slanted flames, the centre of curvature may even be found outside the tube (Fig.6-b) but this results from erroneous measurements when cell splitting occurs at the flame tip, leading to false evaluation of the radius of curvature with too large values, or when the very curved part of the flame close to the wall is not clearly seen on the images. It can be seen that even axial ignition doesn't lead to really axisymmetric flames since the centre of curvature is slightly off-axis (Fig.6-b). The same trends are observed in lean and stoichiometric mixtures of propane and methane-air in both tubes (54 and $94 \mathrm{~mm}$ ), but the situation is much more confusing in rich mixtures, in which case there is no clear distinction between both types of ignition (Fig.7). 


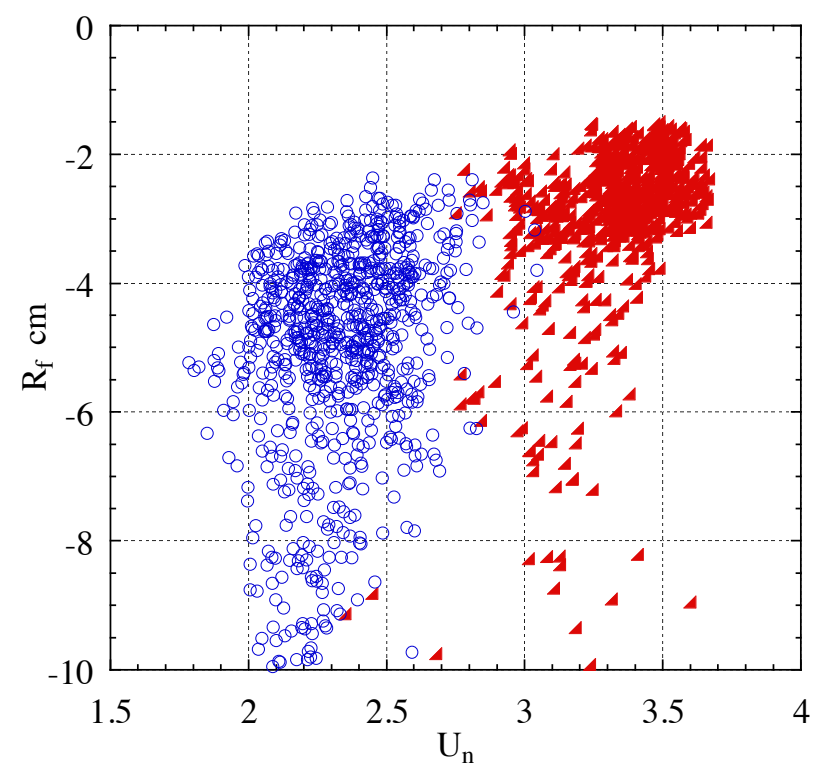

Figure 6-a

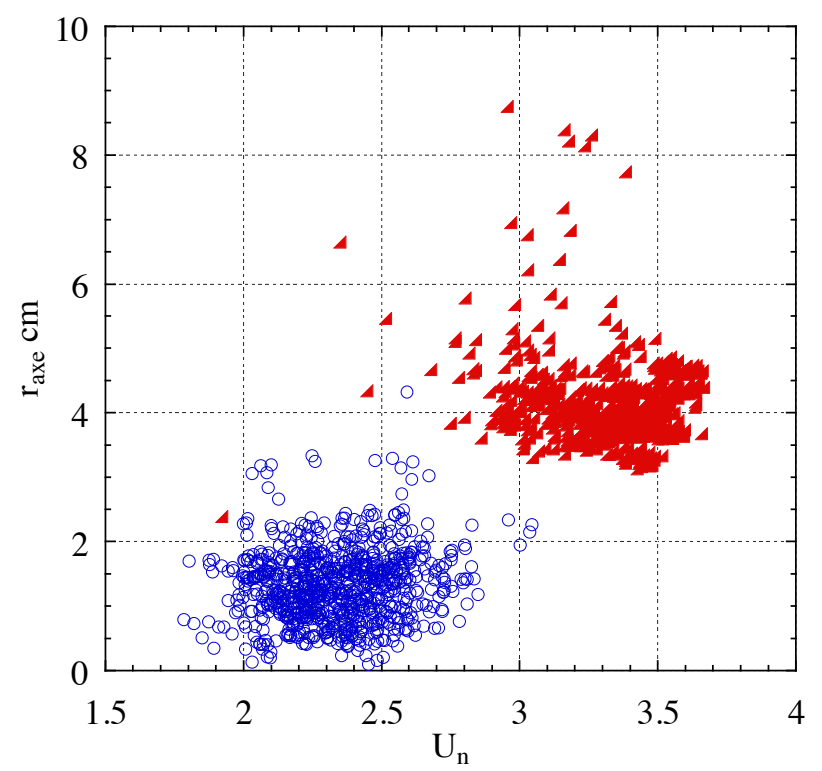

Figure 6-b

Figure 6: Effective radius of curvature (a) and radial position of the centre of curvature (b) as a function of the normalized flame speed $\mathrm{U}_{\mathrm{n}}=\mathrm{U}_{\mathrm{t}} / \mathrm{U}_{\mathrm{L}}$.

Stoichiometric propane-air flame, tube $\varnothing=94 \mathrm{~mm} . \bigcirc=$ axial ignition, $\boldsymbol{\Lambda}=$ lateral ignition. 


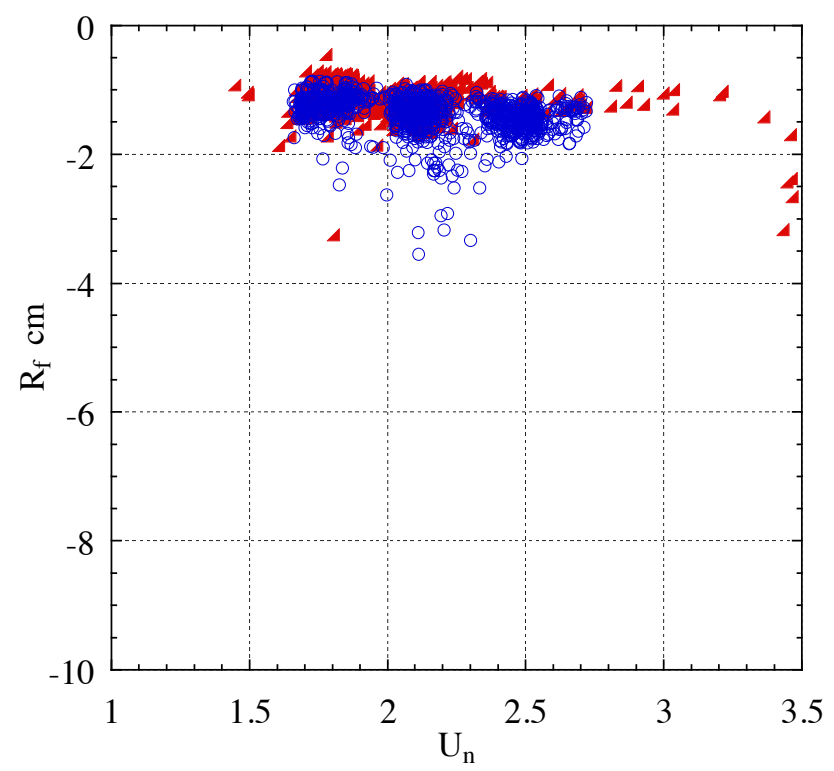

Figure 7: Effective radius of curvature as a function of the normalized flame speed $U_{n}=U_{t} / U_{L}$. Rich propane-air flame $\phi=1.4$, tube $\emptyset=94 \mathrm{~mm} . \bigcirc=$ axial ignition, $\boldsymbol{\Lambda}=$ lateral ignition .

Thus even if the mean velocity of premixed flames propagating freely in tubes has generally two distinct ranges of values depending on the global symmetry of the flame, a result not expected from the MichelsonSivashinsky analyses, it appears that the instantaneous velocities of propagation could sustain the ideas developed in these analyses: there is more than two stationary solutions when the ratio tube radius/ cut-off length is large as is the case in rich propane-air mixtures, so small perturbations of the flame can induce jumps between a great number of discrete solutions with different velocities of propagation

\section{3: Discussion}

A statistical analysis of these data (Fig.8) gives access to some characteristic lengths of the flame such as the most probable value (noted here $\mathrm{R}^{*}$ ) or the minimal value (noted $\mathrm{R}_{\min }$ ). The mean value, generally larger than $\mathrm{R}^{*}$, is not used here as it is probably biased by erroneous measurements. Slanted flames have a much narrower distribution of radius of curvature and peak at a smaller value, with also a smaller minimal radius of curvature. In order to compare these results to numerical models, we have to evaluate the cut-off wavelength in each configuration. According to analytical calculations of the stability of premixed planar flames including expansion effects, gravity and preferential diffusion [1,28,31], and for downward propagating flames above the threshold of cellular instability, there is a band of unstable wavelengths limited by two neutral wave numbers:

$$
k_{n}^{ \pm}=\frac{E-1}{4 E M_{a} d_{L}}\left(1 \pm \sqrt{1-\frac{8 M_{a} d_{L} g}{(E-1) U_{L}^{2}}}\right)
$$

where $\mathrm{E}$ is the expansion ratio $\mathrm{E}=\boldsymbol{\rho}_{\mathrm{u}} / \boldsymbol{\rho}_{\mathrm{b}}$ given by GASEQ [32], Ma is the Markstein number, $\mathrm{d}_{\mathrm{L}}$ the laminar flame thickness taken equal to $D_{\mathrm{th}} / \mathrm{U}_{\mathrm{L}}$ with $\mathrm{D}_{\mathrm{th}}=0.2 \mathrm{~cm}^{2} \mathrm{~s}^{-1}$ the thermal diffusivity in the unburnt gases, and $\mathrm{g}$ the acceleration of gravity. The subscripts $u$ and $b$ refer respectively to unburnt and burnt gases. Using the values of Ma determined by Davis et al. [33] and following the same approach as in [28], three characteristic lengths can be calculated:

- The largest unstable wavelength $\Lambda_{\max }=2 \pi / \mathrm{k}_{\mathrm{n}}{ }^{-}$is in the range 0.4 to $0.9 \mathrm{~m}$ for methane and 0.2 to $0.6 \mathrm{~m}$ for propane. It is much larger than the burner diameter in these experiments so it can be disregarded.

- The smallest unstable wavelength $\lambda_{\mathrm{c}}=2 \pi / \mathrm{k}_{\mathrm{n}}{ }^{+}$, characteristic of the cut-off wavelength used in the models.

- The most unstable wavelength $\Lambda^{*} \sim 2 \lambda_{\text {c. }}$ 


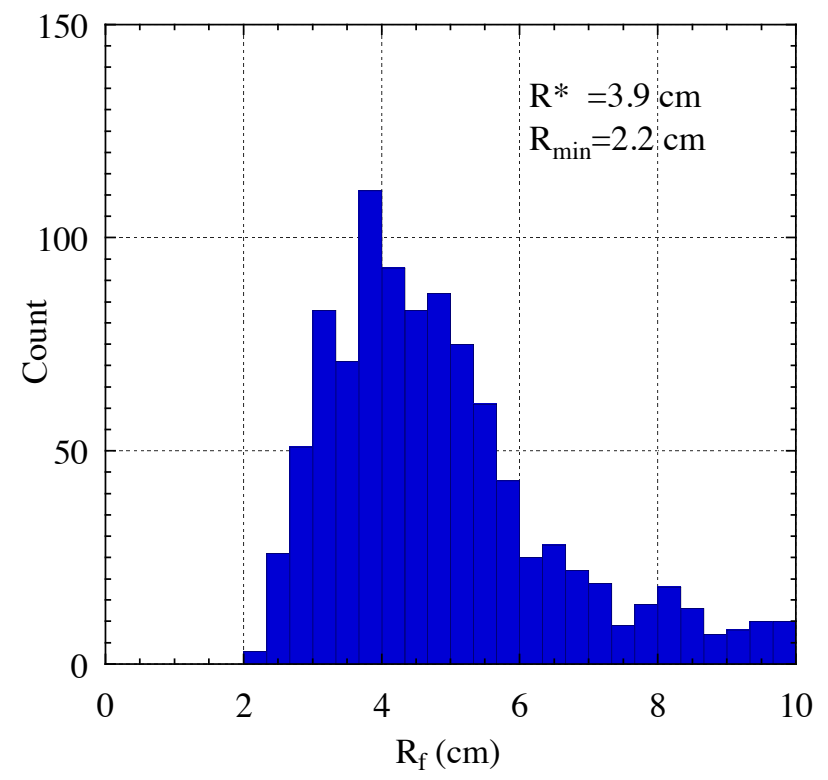

Figure 8-a

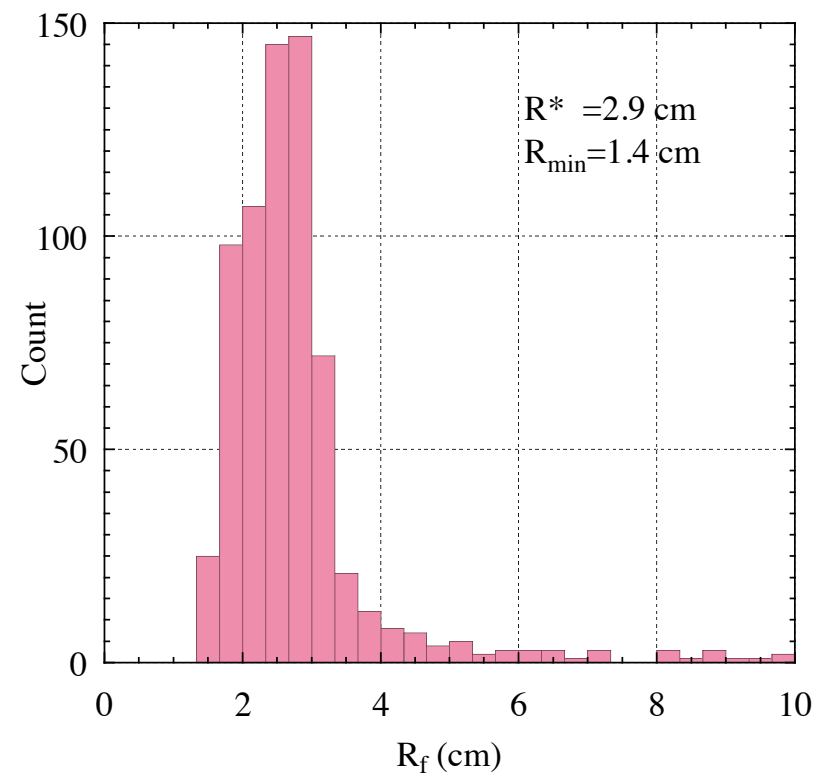

Figure 8-b

Figure 8: Histograms of the radius of curvature at the flame tip in both ignition conditions.

Stoichiometric propane-air flame, tube $\varnothing=94 \mathrm{~mm}$. a) axial ignition; b) lateral ignition.

These values are reported in Table I and on the Figure 9. The differences between axial and lateral ignition were not systematically observed in the smaller tube, especially with lean methane and rich propane mixtures in which case the flame was generally slanted, and with rich methane-air flames that were almost symmetrical. In each configuration, the evolution of the characteristic radius of curvature at the flame tip, the most probable $\mathrm{R}^{*}$ or the minimal value $\mathrm{R}_{\min }$, reflects the evolution of the intrinsic characteristic wavelengths, the most amplified wavelength $\Lambda^{*}$ or the cut-off wavelength $\lambda_{\mathrm{c}}$. These values increase with equivalence ratio for methane-air flames while they decrease for propane-air flames. The striking result is that the minimal radius of curvature is almost equal to $\mathrm{R}_{\min } \sim \Lambda^{*} \sim 2 \lambda_{\mathrm{c}}$, while the most probable value $\mathrm{R}^{*}$ is of the order of $3 \Lambda^{*}$ and even $4.5 \Lambda^{*}$ with stoichiometric methane-air flames in the wider tube. Such results were already obtained either by determining at which size cells produced by the Darrieus-Landau instability are prone to secondary instabilities [21,27], or in numerical modelling of the Sivashinsky equation [14,34]. But to the authors' knowledge, no experimental measurements were done with flames propagating freely in a tube. In Sivashinsky simulation [34], an initially flat flame is submitted to noise perturbations and evolved with a characteristic time $t_{\mathrm{LD}} \sim 0.5 \lambda_{\mathrm{c}} / \mathrm{U}_{\mathrm{L}}$ corresponding to the time of growth of the most unstable wavelength. In the early stage, $t<2 t_{L D}$, there is a linear development of a cellular structure with a 
wavelength of the order of the most unstable wavelength. Then, after a while that depends on the noise level $\mathrm{u}^{\prime} / \mathrm{U}_{\mathrm{L}}$, the cells start to coalesce with a linear increase of wavelength up to a point where the stabilizing effects due to curvature, roughly proportional to $\mathrm{EU}_{\mathrm{L}} / \mathrm{R}$ [14], are too weak to support noise perturbations. A stationary state is finally obtained where cells splitting compensates for cells coalescence that produces a limiting mean wavelength $\Lambda_{\infty}$ that is thus function of the noise level. In the simulation [34], this occurs at a time $\mathrm{t}_{\infty}$ such that $\Lambda_{\infty} \sim 10 \lambda_{\mathrm{c}}$ at $\mathrm{t}_{\infty} / \mathrm{t}_{\mathrm{LD}}=30$ when $\mathrm{u}^{\prime} / \mathrm{U}_{\mathrm{L}}=1 / 1000$, or $\Lambda_{\infty} \sim 4 \lambda_{\mathrm{c}}$ at $\mathrm{t}_{\infty} / \mathrm{t}_{\mathrm{LD}}=10$ when $\mathrm{u}^{\prime} / \mathrm{U}_{\mathrm{L}}=1 / 10$.

The transit time in the burner $1.5 \mathrm{~m}$ long is generally much larger than this limiting time $\mathrm{t}_{\infty}$, so a stationary propagation of the flame can be assessed. The fact that $R_{\min } \sim 2 \lambda_{c}$ let us suppose that curvature effects with this radius of curvature are sufficient to overcome the hydrodynamic instability in the cases studied. Then $\mathrm{R}^{*}$ can reach values as large as $4.5 \mathrm{~L}^{*} \sim 9 \lambda_{\mathrm{c}}$ without occurrence of the secondary instability, confirming the smallness of upstream perturbations. But it has to be noticed that our measurements are made at the leading bump, where the velocity field induced by the whole shape of the flame in the upstream gases can be very different from the one simulated with a flat flame on average. This is particularly true for slanted flames, which are also probably affected by boundary layer effects, and for which the fully developed flame cells are likely to appear on the flame skirt rather than at the leading bump.

Nevertheless, apart from the differences in the velocity of propagation between slanted and axisymmetric flames, these measurements are consistent with the results of numerical modelling of the Sivashinsky equation: the minimal radius of curvature is almost equal to the most unstable wavelength calculated from the linear theory, and flames with a small radius of curvature at the leading bump have a narrower range of fluctuations of their radius of curvature, reflecting a narrower range of unstable wavelengths due to stabilizing effects of curvature. The most probable radius of curvature can be very large, up to $9 \lambda_{\mathrm{c}}$. It increases with the tube diameter and is generally larger in the case of axial ignition. No simple relation with $\lambda_{c}$ can be obtained from this study, but the most probable value $\mathrm{R}^{*}$ is comparable to the value of $\Lambda_{\infty}$ calculated with non-linear theories. 


\begin{tabular}{|c|c|c|c|c|c|c|c|c|}
\hline & \multicolumn{3}{|c|}{$\begin{array}{c}\text { Methane-air, } \phi=0.8, \mathrm{U}_{\mathrm{L}}=23.6 \mathrm{~cm} / \mathrm{s} \\
\Lambda^{*}=1.2 \mathrm{~cm}, \lambda_{\mathrm{c}}=0.65 \mathrm{~cm}\end{array}$} & \multicolumn{3}{c|}{$\begin{array}{c}\text { Propane-air, } \phi=0.8, \mathrm{U}_{\mathrm{L}}=29.8 \mathrm{~cm} / \mathrm{s} \\
\Lambda^{*}=1.5 \mathrm{~cm}, \lambda_{\mathrm{c}}=0.8 \mathrm{~cm}\end{array}$} \\
\hline & \multicolumn{2}{|c|}{ Tube $\varnothing=54 \mathrm{~mm}$} & \multicolumn{2}{|c|}{ Tube $\varnothing=94 \mathrm{~mm}$} & \multicolumn{3}{c|}{ Tube $\varnothing=54 \mathrm{~mm}$} & \multicolumn{2}{c|}{ Tube $\varnothing=94 \mathrm{~mm}$} \\
\hline Ignition & Axial & Lateral & Axial & Lateral & Axial & Lateral & Axial & Lateral \\
\hline $\mathrm{R}^{*}(\mathrm{~cm})$ & & 2,15 & 4,15 & 2,5 & 2,15 & 2,8 & 4 & 3,2 \\
\hline $\mathrm{R}_{\min }(\mathrm{cm})$ & & 1,4 & 1,5 & 1,4 & 1,5 & 1,7 & 2 & 1,9 \\
\hline $\mathrm{U}_{\mathrm{t}} / \mathrm{U}_{\mathrm{L}}$ & & 2,5 & 1,9 & 3 & 1,5 & 2,5 & 2,3 & 3,1 \\
\hline
\end{tabular}

\begin{tabular}{|c|c|c|c|c|c|c|c|c|}
\hline \multirow[b]{3}{*}{ Ignition } & \multicolumn{4}{|c|}{ 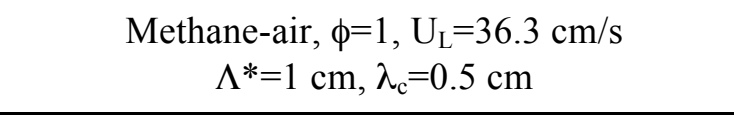 } & \multicolumn{4}{|c|}{$\begin{array}{c}\text { Propane-air, } \phi=1, \mathrm{U}_{\mathrm{L}}=42.1 \mathrm{~cm} / \mathrm{s} \\
\Lambda^{*}=1.05 \mathrm{~cm}, \lambda_{\mathrm{c}}=0.54 \mathrm{~cm}\end{array}$} \\
\hline & \multicolumn{2}{|c|}{ Tube $\emptyset=54 \mathrm{~mm}$} & \multicolumn{2}{|c|}{ Tube $\varnothing=94 \mathrm{~mm}$} & \multicolumn{2}{|c|}{ Tube $\varnothing=54 \mathrm{~mm}$} & \multicolumn{2}{|c|}{ Tube $\varnothing=94 \mathrm{~mm}$} \\
\hline & Axial & Lateral & Axial & Lateral & Axial & Lateral & Axial & Lateral \\
\hline $\mathrm{R}^{*}(\mathrm{~cm})$ & 2,8 & 2,3 & 4,5 & 2,8 & 2,8 & 2,5 & 3,9 & 2,9 \\
\hline $\mathrm{R}_{\min }(\mathrm{cm})$ & 1,1 & 1 & 1,5 & 1,5 & 1,4 & 1 & 2,2 & 1,4 \\
\hline $\mathrm{U}_{\mathrm{t}} / \mathrm{U}_{\mathrm{L}}$ & 1,9 & 2,6 & 2,1 & 3,3 & 1,8 & 2,7 & 2,3 & 3,4 \\
\hline
\end{tabular}

\begin{tabular}{|c|c|c|c|c|c|c|c|c|}
\hline & \multicolumn{3}{|c|}{$\begin{array}{c}\text { Methane-air, } \phi=1.3, \mathrm{U}_{\mathrm{L}}=26.3 \mathrm{~cm} / \mathrm{s} \\
\Lambda^{*}=2.1 \mathrm{~cm}, \lambda_{\mathrm{c}}=1.2 \mathrm{~cm}\end{array}$} & \multicolumn{3}{c|}{$\begin{array}{c}\text { Propane-air, } \phi=1.4, \mathrm{U}_{\mathrm{L}}=22.6 \mathrm{~cm} / \mathrm{s} \\
\Lambda^{*}=0.8 \mathrm{~cm}, \lambda_{\mathrm{c}}=0.4 \mathrm{~cm}\end{array}$} \\
\hline & \multicolumn{2}{|c|}{ Tube $\varnothing=54 \mathrm{~mm}$} & \multicolumn{2}{|c|}{ Tube $\varnothing=94 \mathrm{~mm}$} & \multicolumn{2}{c|}{ Tube $\varnothing=54 \mathrm{~mm}$} & \multicolumn{2}{c|}{ Tube $\varnothing=94 \mathrm{~mm}$} \\
\hline Ignition & Axial & Lateral & Axial & Lateral & Axial & Lateral & Axial & Lateral \\
\hline $\mathrm{R}^{*}(\mathrm{~cm})$ & 3 & 3,5 & 2,9 & & 1,8 & 1,3 & 1,1 \\
\hline $\mathrm{R}_{\text {min }}(\mathrm{cm})$ & 2 & 2,2 & 2,2 & & 0,8 & 0,9 & 0,5 \\
\hline $\mathrm{U}_{\mathrm{t}} / \mathrm{U}_{\mathrm{L}}$ & 1,5 & 1,4 & 2,1 & & 2,6 & 1,1 & 2,5 \\
\hline
\end{tabular}

Table I: Characteristic length scales and normalized self-turbulent flame speed measured in tubes of internal diameter 54 and $94 \mathrm{~mm}$. 

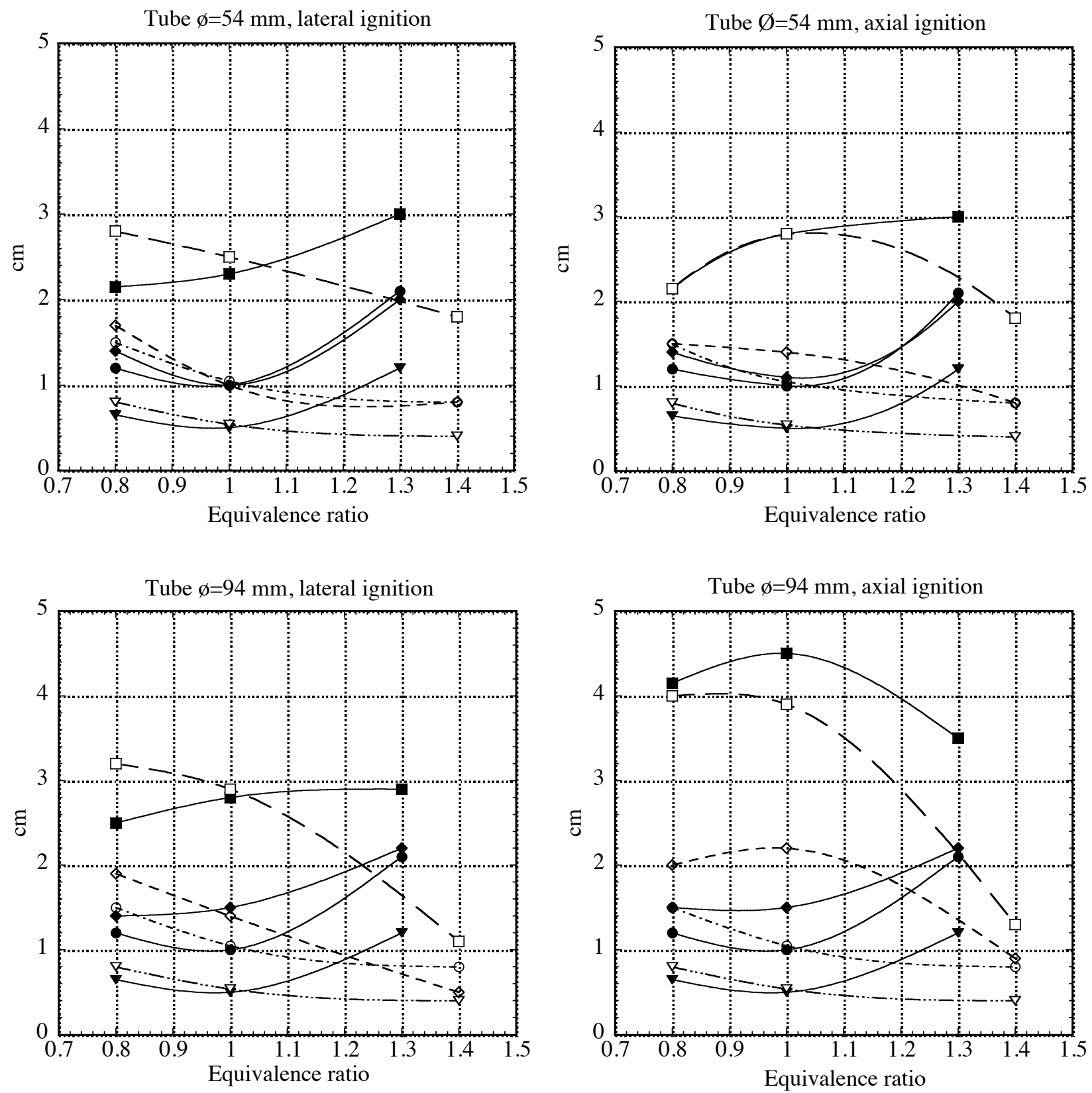

Figure 9: Characteristic lengths of methane-air (full symbols, full lines) and propane-air flames (open symbols, dash-dotted lines) as a function of the tube diameter and of the symmetry of ignition.

$\left(\bullet, \circ=\Lambda^{*} ; \boldsymbol{\nabla}, \nabla=\lambda_{\mathrm{c}} ; \mathbf{\square}, \square=\mathrm{R}^{*} ; \bullet, \diamond=\mathrm{R}_{\min }\right)$. Lines represent only a smoothed interpolation between the calculated or measured values.

\section{Conclusion}

Experiments were performed to analyse premixed flames propagating freely in wide tubes, first to give a better description of the two regimes of propagation already observed, then to relate their characteristic length scales to the cut-off wavelength used in numerical modelling of premixed flames dynamics.

Slanted flames propagate at a speed 50\% larger than quasi-symmetric flames, three to four times the normal flame speed. This can be relevant for determining the flame flashback conditions.

The variations of flame speed at the leading bump precede the variations in the flame surface, indicating that the local condition at the flame tip is the critical phenomenon that controls the flame propagation. This 
is confirmed by the correlation between the local radius of curvature and the flame speed, slower flames having a larger radius of curvature.

The dynamics of the flame resembles the one described by the Michelson-Sivashinsky equation: slanted flames with a small radius of curvature have a restricted range of fluctuations, reflecting the stabilizing effect of curvature; the minimal radius of curvature is of the order of the most unstable wavelength $\Lambda^{*} \sim 2 \lambda_{\mathrm{c}}$ and the most probable radius of curvature can be compared to the limiting value $\Lambda_{\infty}$ calculated with nonlinear theories.

Acknowledgments:

Recurrent funding from the French CNRS and Aix-Marseille University supported this work. 
References:

1/ Clavin P., Premixed Combustion and Gasdynamics, Ann. Rev. Fluid Mech. 26, p321 (1994).

2/ Bychkov V. V., Libeman M. A., Dynamics and stability of premixed flames, Phys. Rep. 325, p115 (2000).

3/ Gostintsev Yu. A., Istratov A.G., Shulenin Yu.V., Self-similar propagation of a free turbulent flame in premixed gas mixtures, Combustion Explosions and Shock Waves 24(5), 563-569 (1988).

4/ Bradley D., Cresswell T.M., Puttock J.S., Flame Acceleration Due to Flame-Induced Instabilities in Large-Scale Explosions, Combust. Flame 124, p. 551-559 (2001).

5/ Kobayashi H., Tamura T., Maruta K., Niioka T., Williams F.A., Burning Velocity of Turbulent Premixed Flames in a High-pressure Environment, Proc. Combust. Inst. 26, 389-396 (1996).

6/ Savarianandan V.R., Lawn C.J., Burning velocity of premixed turbulent flames in the weakly wrinkled regime, Combust. Flame 146, pp1-18 (2006).

7/ Sivashinsky G., Nonlinear analysis of hydrodynamic instability in laminar flames ; Part 1 : Derivation of basic equations, Acta Astronaut. 4, 1117 (1977).

8/ Frankel M., An equation of surface dynamics modelling flame fronts as density discontinuities in potential flows, Phys. Fluids A, 2, 1879 (1990).

9/ Thual O., Frisch U., Henon M., Application of pole decomposition to an equation governing the dynamics of wrinkled flame fronts, J. Phys. France, 46, 1485 (1985).

10/ D'angelo Y., Joulin G., Boury G., On model evolution equations for the whole surface of threedimensional expanding wrinkled premixed flames, Comb. Theory and Modelling, 4 (3), 317-338 (2000).

11/ Guy Joulin, On the hydrodynamic stability of curved premixed flames, J. Phys. France 50, 1069-1082 (1989)

12/ G. Joulin, B. Denet, H. El-Rabii, Potential-flow models for channelled two-dimensional premixed flames around near-circular obstacles, Phys. Rev. E 81, 016314 (2010).

13/ Denet B., Joulin G., Wrinkled flames and geometrical stretch, Phys. Rev E 84, 016315 (2011)

14/ Michelson D.M., Sivashinsky G.I., Thermal expansion induced cellular flames, Combust. Flame 48, 211-217 (1982).

15/ Karlin V. Sivashinsky G., Asymptotic modelling of self-acceleration of spherical flames, Proc.

Combust. Inst. 31, p.1023-1030 (2007)

16/ Fursenko R. V., Pan K. L., Minaev S. S., Noise influence on pole solutions of the Sivashinsky equation for planar and outward propagating flames, Phys. Rev E 78, 056301 (2008)

17/ Denet B., Sivashinsky equation in a rectangular domain, Phys. Rev E 75, 046310 (2007)

18/ Searby G., Truffaut J-M., Joulin G., Comparison of experiments and a nonlinear model equation for spatially developing flame instability, Phys. Fluids 13, 3270-3276 (2001)

19/ Cambray P., Joulin G., On a Scaling Law for Coarsening Cells of Premixed Flames: an Approach to Fractalization, Combust. Sci. and Tech., 2000, Vol. 161.pp. 139·164

20/ Mukaiyama K, Shibayama S., Kuwana K., Fractal structures of hydrodynamically unstable and diffusive-thermally unstable flames, Combust. Flame 160, p. 2471-2475 (2013).

21/ Akkerman V., Bychkov V., Velocity of weakly turbulent flames of finite thickness, Comb. Theory and Modelling, 9:2, p. 323-351 (2005).

22/ Kadowaki S., Suzuki H., Kobayashi H., The unstable behavior of cellular premixed flames induced by intrinsic instability, Proc. Combust. Inst. 30, p. 169-176 (2005).

23/ Clavin P.,Searby G., Weakly turbulent wrinkled flames in premixed gases, Combust. Sci. Technol. 46; 167-194 (1986).

24/ Gülder O. M., Smallwood G. J., Inner cutoff scale of flame surface wrinkling in turbulent premixed flames, Combust. Flame 103: p.107-114 (1995).

25/ Renou B., Boukhalfa A., Puechberty D., Trinité M., Local scalar flame properties of freely propagating premixed turbulent flames at various Lewis numbers, Combust. Flame 123: p. 507-521 (2000).

26/ Bychkov, V., Kleev, A., The nonlinear equation for curved flames applied to the problem of flames in cylindrical tubes, Phys. Fluids 11(7), p. 1890-1895 (1999).

27/ Liberman, M.A., Ivanov, M.F., Peil, O.E., Valiev, D.M., Eriksson, L.-E., Numerical studies of curved stationary flames in wide tubes, Comb. Theory and Modelling 7(4), p. 653-676 (2003).

28/ Quinard J., Searby G., Denet B., Graña-Otero J., Self-Turbulent Flame Speeds, Flow Turbulence Combust 89:231-247 (2012).

29/ Denet, B., Stationary solutions and Neumann boundary conditions in the Sivashinsky equation, Phys.

Rev. E 74, 036303 (2006).

30/ Bosschaart, K.J., De Goey, L.P.H., The laminar burning velocity of flames propagating in mixtures 
of hydrocarbons and air measured with the heat flux method, Combust. Flame 136, p. 264-269 (2004). 31/ Quinard, J., Searby, G., Boyer, L., Stability limits and critical size of structures in premixed flames, Prog. Astronaut. Aeronaut. 95, p. 129-141 (1985).

32/ Morley, C.: Gaseq a chemical equilibrium program for windows (2005). http://www.gaseq.co.uk/ 33/ Davis, S.G., Quinard, J., Searby, G., Markstein numbers in counterflow, methane- and propane-air flames: a computational study, Combust. Flame 130, p. 123-136 (2002).

34/ Cambray P., Joulain K., Joulin G., Mean Evolution of Wrinkle Wavelengths in a Model of WeaklyTurbulent Premixed Flame, Combust. Sci. and Tech., 103, p. 265-282 (1994). 


\section{Figures captions :}

Figure 1: Experimental set-up

Figure 2: Image processing to determine the position of the flame tip and the radius of curvature in each orthogonal section (left and right images on each picture; middle image : direct view of the flame).

Propane-air flame, $\phi=1.0$, tube $\varnothing 94 \mathrm{~mm}$. a) axial ignition; b) lateral ignition.

Figure 3: Trajectories of methane-air flames in a tube $\varnothing=94 \mathrm{~mm}$ as a function of initial conditions for ignition. Full lines: lateral ignition; dashed lines: axial ignition.

Figure 4: Histogram of stoichiometric propane-air flame velocities in a tube $\varnothing=94 \mathrm{~mm}$ as a function of initial conditions for ignition. Hatched/ full shading: lateral/axial ignition.

Figure 5: Time traces of the instantaneous flame speed at the tip (full line) and integrated luminosity (left image, dash-dotted line) or mean flame speed (right image, dash-dotted line).

a) Methane-air flame, $\phi=1$, tube $\varnothing=54 \mathrm{~mm}$; b) Michelson-Sivashinsky simulation with $10 \%$ Gaussian white noise in space and time.

Figure 6: Effective radius of curvature (a) and radial position of the centre of curvature (b) as a function of the normalized flame speed $\mathrm{U}_{\mathrm{n}}=\mathrm{U}_{\mathrm{t}} / \mathrm{U}_{\mathrm{L}}$.

Stoichiometric propane-air flame, tube $\emptyset=94 \mathrm{~mm} . \bigcirc=$ axial ignition, $\boldsymbol{\Lambda}=$ lateral ignition.

Figure 7: Effective radius of curvature as a function of the normalized flame speed $U_{n}=U_{t} / U_{L}$. Rich propane-air flame $\phi=1.4$, tube $\varnothing=94 \mathrm{~mm} . \mathrm{O}=$ axial ignition, $\boldsymbol{\Lambda}=$ lateral ignition.

Figure 8: Histograms of the radius of curvature at the flame tip in both ignition conditions.

Stoichiometric propane-air flame, tube $\varnothing=94 \mathrm{~mm}$. a) axial ignition; b) lateral ignition.

Figure 9: Characteristic lengths of methane-air (full symbols, full lines) and propane-air flames (open symbols, dash-dotted lines) as a function of the tube diameter and of the symmetry of ignition.

$\left(\bullet, \circ=\Lambda^{*} ; \boldsymbol{\nabla}, \nabla=\lambda_{\mathrm{c}} ; \boldsymbol{\nabla}, \mathrm{\square}=\mathrm{R}^{*} ; \bullet, \diamond=\mathrm{R}_{\min }\right)$. Lines represent only a smoothed interpolation between the calculated or measured values.

Table I: Characteristic length scales and normalized self-turbulent flame speed measured in tubes of internal diameter 54 and $94 \mathrm{~mm}$. 